\section{Are Pharmacy Students Learning To Be Effective Collaborators and To Work within Health Care Teams through Our Interprofessional Education Initiatives?}

\section{THE "PRO" SIDE}

The drivers for both interprofessional education and interprofessional collaboration are compelling, and they exemplify the magnitude and complexity of the issues relevant to interprofessional working relationships. However, before we debate whether pharmacy has sufficiently embraced and advanced the "interprofessional education for interprofessional collaboration" movement, it is important to examine the global and Canadian health care delivery contexts. Avoidable adverse events — known markers of health care quality and patient safety — are estimated to be the eighth leading cause of death in the United States. ${ }^{1}$ The global shortage of health care providers is at a point of crisis: as long ago as 2006, the World Health Organization estimated a worldwide shortage of about 4.3 million health workers. ${ }^{2}$ In 2003, the government of Canada acknowledged that its health care delivery system was no longer affordable or sustainable and that dramatic health care reform was required. ${ }^{3}$

Worldwide, interprofessional education and interprofessional collaboration have been identified as innovative strategies that can, at a minimum, mitigate these concerns. Mounting evidence suggests that these strategies improve patient safety, access to care, lengths of hospital stay, and quality of life for patients and families. ${ }^{4}$ Other studies have noted improved job satisfaction and better recruitment and retention of health care providers working on interprofessional collaborative teams. ${ }^{5-7}$ In 2005, the Canadian government responded by allocating more than $\$ 20$ million over 3 years, mostly to postsecondary institutions, to the Interprofessional Education for Collaborative Person-Centred Practice Initiative (www.hc-sc.gc.ca/hcs-sss/pubs/hhrhs/2008-ar-ra/indexeng.php\#iecppc).

As a consequence of this strategic Health Canada investment, there have been tremendous advances toward this form of education and practice within pharmacy in Canada. For example, the Association of Faculties of Pharmacy of Canada has explicitly identified "Collaborator Role" as 1 of 7 educational outcome categories. ${ }^{8}$ Similarly, the National Association of Pharmacy Regulatory Authorities has identified "intra and inter-professional collaboration" as 1 of 9 competency categories. ${ }^{9}$ The Pharmacy Examining Board of Canada's revised qualifying examination blueprint (parts I and II) specifies that $6 \%$ of the overall exam be allocated to the assessment of intra- and inter-professional collaboration. ${ }^{10}$ Similar educational and licensing requirements are in place for registered and licensed practical nurses, occupational therapists, physical therapists, and family physicians, who are therefore significant enablers and drivers of interprofessional learning.

As a partner in a pivotal Health Canada-funded project entitled Accreditation of Interprofessional Health Education, the Canadian Council for Accreditation of Pharmacy Programs has recently dedicated one entire standard (Standard 3) to interprofessional education. ${ }^{11-13}$ Again, pharmacy is not alone in this effort, with an additional 7 accrediting organizations for 5 other health professions participating in and making a commitment to the project. When accreditation, regulatory, licensing, and assessment organizations are all looking for evidence of interprofessional education for collaborative person-centred practice in the structures, processes, and outcomes of health professional education, academic institutions, including colleges and faculties of pharmacy, must respond.

And indeed they have. Looking for evidence that pharmacy students are learning to become effective interprofessional collaborators through their prelicensure training, I undertook a quick web-based search to locate relevant information about interprofessional education coordinated through the home universities of the 10 colleges and faculties of pharmacy in Canada. To more specifically address the question under debate, I followed 2 key learning principles during this web search: first, that explicitly stated educational outcomes should inform the progression of learning and second, that the progression of learning should be intentionally structured along a continuum or a scaffolded curriculum, to allow for transfer of learning across increasingly complex tasks. ${ }^{14}$ In keeping with these principles, my search involved an examination of whether interprofessional collaborative competencies were specified and whether interprofessional learning opportunities were offered along a learning continuum to achieve those competencies. The sources were also searched to confirm pharmacy students' involvement in any interprofessional learning opportunities that were offered. Finally, recognizing the importance of faculty as "ambassadors" of interprofessional education, to advance the cause within and between stakeholder organizations, I examined the sources to determine whether faculty development was offered in this area. 
The results provide convincing evidence that students from all 10 colleges and faculties of pharmacy across Canada are given opportunities to participate in interprofessional learning within their respective institutions (Table 1). All institutions have either a specific website or an interfaculty committee (or both) to serve as the "hub" of information on interprofessional education and interprofessional collaboration. All institutions have developed interprofessional learning outcomes to guide development of their interprofessional curriculum, with 7 of the 10 colleges using or adapting the 6 collaborative competency domains specified in the national competency framework of the Canadian Interprofessional Health Collaborative. ${ }^{29}$ All institutions have articulated or illustrated a learning continuum to achieve competence in the stated interprofessional learning outcomes. When noted in the sources, the diversity of professions involved in program planning was impressive, with between 9 and 15 health professional programs participating. Finally, the websites of 6 of the 10 universities noted faculty development in interprofessional education.

We should also not underestimate the power of students as positive catalysts for change and the importance of socialization in their developing interprofessional collaborative relationships. The National Health Sciences Students' Association is a studentinspired organization established in Canada in 2005 as a network of university- and college-based chapters with a mandate to promote interprofessional education for interprofessional collaboration, facilitate opportunities for interprofessional interactions, and foster student champions to lead interprofessional efforts. The group has survived the test of time and is now in its 11th year of existence. Notably, leaders from the national health care student associations, including the Canadian Association of Pharmacy Students and Interns, are working through the National Health Sciences Students' Association to achieve greater collaboration at the national level (https://www.facebook.com/NaHSSA/).

In conclusion, the university health sciences faculties that are home to the 10 colleges of pharmacy across the country have responded to the demand for health system transformation through the Interprofessional Education for Collaborative Person-Centred Practice Initiative. Within all 10 universities, the colleges of pharmacy are actively involved in this process. With a grounding in sound educational theory, pharmacy students are being offered interprofessional learning opportunities along the learning continuum to achieve competence in interprofessional collaboration

\section{References}

1. Knebel E, Greiner AC, editors. Health professions education: a bridge to quality. Washington (DC): National Academies Press; 2003.

2. The world health report, 2006 working together for health. Geneva (Switzerland): World Health Organization; 2006.

3. Health human resource strategy (HHRS). Ottawa (ON): Health Canada; [modified 2011 Jul 7; cited 2016 May 11]. Available from: www. hc-sc.gc.ca/hcs-sss/hhr-rhs/strateg/index-eng.php

4. Gilbert JH, Yan J, Hoffman SJ. A WHO report: framework for action on interprofessional education and collaborative practice. $J$ Allied Health. 2010;39 Suppl 1:1967.

5. Zwarenstein M, Goldman J, Reeves S. Interprofessional collaboration: effects of practice-based interventions on professional practice and healthcare outcomes. Cochrane Database Syst Rev. 2009;(3):CD000072.

6. Reeves S, Perrier L, Goldman J, Freeth D, Zwarenstein M. Interprofessional education: effects on professional practice and healthcare outcomes (update). Cochrane Database Syst Rev. 2013;(3):CD002213.

\section{Table 1. Interprofessional Education at the 10 Colleges and Faculties of Pharmacy in Canada*}

\begin{tabular}{|c|c|c|c|}
\hline Institution & Educational Outcomes & No. of Professions & $\begin{array}{c}\text { Faculty } \\
\text { Development }\end{array}$ \\
\hline $\begin{array}{l}\text { University of } \\
\text { British Columbia }{ }^{15,16}\end{array}$ & $\begin{array}{l}\text { CIHC national competency } \\
\text { framework }\end{array}$ & $\begin{array}{l}15 \text { health and human service programs, } \\
\text { including pharmacy }\end{array}$ & Yes \\
\hline University of Alberta ${ }^{17}$ & $\begin{array}{l}\text { Communication, collaboration, } \\
\text { role clarification, reflection, } \\
\text { patient-centred care }\end{array}$ & $\begin{array}{l}14 \text { health sciences programs, } \\
\text { including pharmacy }\end{array}$ & Yes \\
\hline University of Saskatchewan ${ }^{18}$ & CIHC national competency framework & 10 health professions, including pharmacy & Not specified \\
\hline University of Manitobat ${ }^{19,20}$ & CIHC national competency framework & 13 academic units, including pharmacy & Yes \\
\hline University of Toronto ${ }^{21}$ & $\begin{array}{l}\text { Values and ethics, communication, } \\
\text { collaboration }\end{array}$ & $\begin{array}{l}11 \text { health sciences programs, } \\
\text { including pharmacy }\end{array}$ & Yes \\
\hline University of Waterloo ${ }^{22}$ & CIHC national competency framework & Not specified & Not specified \\
\hline Université Laval23,24 & CIHC national competency framework & $\begin{array}{l}\text { Mandatory for } 9 \text { professions } \\
\text { (including pharmacy), optional for } \\
1 \text { profession }\end{array}$ & Yes \\
\hline Université de Montréa|25,26 & $\begin{array}{l}\text { Adapted from CIHC national } \\
\text { competency framework }\end{array}$ & $\begin{array}{l}10 \text { health sciences and psychosocial } \\
\text { sciences training programs, } \\
\text { including pharmacy }\end{array}$ & $\begin{array}{c}\text { Not specified } \\
\text { patients-as-trainers } \\
\text { program }\end{array}$ \\
\hline $\begin{array}{l}\text { Memorial University of } \\
\text { Newfoundland }\end{array}$ & $\begin{array}{l}\text { Roles, teamwork, patient-centred care, } \\
\text { collaborative work }\end{array}$ & $\begin{array}{l}10 \text { schools, centres, and faculties, } \\
\text { including pharmacy }\end{array}$ & Yes \\
\hline Dalhousie University ${ }^{28}$ & CIHC national competency framework & Not specified & Facilitator's guide \\
\hline \multicolumn{4}{|c|}{$\begin{array}{l}\text { CIHC = Canadian Interprofessional Health Collaborative. }{ }^{29} \\
\text { *All colleges and faculties use a learning continuum. } \\
\text { tAs of March } 31,2015, \text { five faculties and schools at the University of Manitoba were amalgamated into one Faculty of Health Science. } \\
\text { At that time, the university's Interprofessional Education Initiative ended, and an Office of Interprofessional Collaboration was created. } \\
\text { Data presented in the table are based on information that was available at the website (www.umanitoba.ca/programs/interprofessional) } \\
\text { on May 11, 2016. }\end{array}$} \\
\hline
\end{tabular}


7. Implementing interprofessional care in Ontario: final report of the Interprofessional Care Strategic Implementation Committee. Toronto (ON): Health Force Ontario; 2010 [cited 2016 May 11]. Available from: www.ipe.uwo.ca/Administration/teachings/HFO\%20IPC\%20Final\%20 Report\%202010.pdf

8. Educational outcomes for first professional degree programs in pharmacy (entry-to-practice pharmacy programs) in Canada. Vancouver (BC): Association of Faculties of Pharmacy of Canada; 2010 [cited 2016 May 11]. Available from: www.afpc.info/sites/default/files/AFPC\%20Educational $\% 20$ Outcomes.pdf

9. Professional competencies for Canadian pharmacists at entry to practice. Ottawa (ON): National Association of Pharmacy Regulatory Authorities; 2014 [cited 2016 May 11]. Available from: http://napra.ca/content_files/ files/comp_for_cdn_pharmacists_at_entrytopractice_march2014_b.pdf

10. Examination blueprint. Toronto (ON): Pharmacy Examining Board of Canada; [cited 2016 May 11]. Available from: www.pebc.ca/index.php/ ci_id/3139/la_id/1.htm

11. Accreditation of interprofessional health education: principles and practices for integrating interprofessional education into the accreditation standards for six health professions in Canada. Ottawa (ON): AIPHE (Accreditation of Interprofessional Health Education) Initiative; 2009 [cited 2016 May 11]. Available from: www.cihc.ca/files/aiphe/resources/AIPHE\%20 Principles\%20and\%20Practices\%20Guide\%20-\%20v.2\%20EN.pdf

12. AIPHE interprofessional health education accreditation standards guide. Phase 2. Ottawa (ON): AIPHE (Accreditation of Interprofessional Health Education) Initiative; 2011 [cited 2016 May 11]. Available from: www.cihc.ca/files/resources/public/English/AIPHE\%20Interprofessional\%20 Health\%20Education\%20Accreditation\%20Standards\%20Guide_EN.pdf

13. Accreditation standards for the first professional degree in pharmacy programs. Toronto (ON): Canadian Council for Accreditation of Pharmacy Programs; [revised 2014 Jul; cited 2016 May 11]. Available from: http://ccapp-accredit.ca/wp-content/uploads/2016/01/CCAPP_ accred_standards_degree_2014.pdf

14. D'Eon M. A blueprint for interprofessional learning. J Interprof Care. 2005;19 Suppl 1:49-59.

15. UBC health [website]. Vancouver (BC): University of British Columbia; [cited 2016 May 11]. Available from: www.chd.ubc.ca

16. Charles G, Bainbridge L, Gilbert J. The University of British Columbia model of interprofessional education. J Interprof Care. 2010;24(1):9-18.

17. Interprofessional learning pathway. Edmonton (AB): University of Alberta, Interprofessional Health Sciences Council; [cited 2016 May 11]. Available from: www.hserc.ualberta.ca/TeachingandLearning/Curriculum/ InterprofessionalLearningPathway.aspx

18. Interprofessional education. Saskatoon (SK): University of Saskatchewan, Health Sciences; [cited 2016 May 11]. Available from: www.healthsciences. usask.ca/educational/interprofessional.php

19. Interprofessional education initiative. Winnipeg (MB): University of Manitoba, Rady Faculty of Health Sciences; [cited 2016 May 11]. Available from: www.umanitoba.ca/programs/interprofessional

20. Grymonpre R, Dean H, James M, Wener P, Ready AE, MacDonald L, et al. Quantifying interprofessional learning in health professional programs: the University of Manitoba experience. Can J Higher Educ. In press.

21. Interprofessional education curriculum: curriculum overview. Toronto (ON): University of Toronto, Centre for Interprofessional Education; 2014 [cited 2016 May 11] Available from: www.ipe.utoronto.ca/interprofessionaleducation-curriculum

22. Waterloo IPE: interprofessional education at Waterloo pharmacy. Waterloo (ON): University of Waterloo; [cited 2016 May 11]. Available from: https:// uwaterloo.ca/pharmacy/waterloo-ipe

23. Bilodeau A, Dumont S, Hagan L, Paré L, Razmpoosh M, Houle N, et al. Interprofessional education at Laval University: building an integrated curriculum for patient-centred practice. J Interprof Care. 2010;24(5):524-35.

24. Milot É, Dumont S, Aubin M, Bourdeau G, Azizah GM, Picard L, et al. Building an interfaculty IPE curriculum: what can we learn from the Université Laval experience? Educ Health (Abingdon). 2015;28(1):58-63.

25. Comité interfacultaire opérationnel de formation à la collaboration. Montréal (QC): Université de Montréal; 2013 [cited 2016 May 11] Available from: http://cio.partenaires-de-soins.ca/?page_id=1176\&lang=en

26. Vanier MC, Therriault PY, Level P, Nolin F, Lefebvre H, Brault I, et al. Innovating in teaching collaborative practice with a large student cohort: Université de Montreal. J Allied Health. 2013;42(4):97E-106E.

27. Enhancing teaching and learning for health professionals. St John's (NL): Memorial University of Newfoundland, Faculty of Medicine, Centre for Collaborative Health Professional Education; 2016 [cited 2016 May 11]. Available from: www.med.mun.ca/CCHPE/Home.aspx
28. Interprofessional education. Halifax (NS): Dalhousie University; [cited 2016 May 11] Available from: www.dal.ca/faculty/interprofessionaleducation.html

29. A national interprofessional competency framework. Vancouver (BC): Canadian Interprofessional Health Collaborative; 2010 [cited 2016 May 11]. Available from: www.cihc.ca/files/CIHC_IPCompetencies_ Feb1210.pdf

\section{Ruby Grymonpre, PharmD, FCSHP}

Professor, College of Pharmacy

University of Manitoba

Winnipeg, Manitoba

Competing interests: None declared.

\section{THE "CON" SIDE}

Although health care has arguably always been delivered by multiple professions, the rise of collaboration as a means to improve patient care outcomes is a relatively new yet increasingly widespread phenomenon. ${ }^{1,2}$ This understanding of care delivery as a "team sport" has led to massive investment in one specific approach to improving teamwork: interprofessional education. ${ }^{3}$ In this article, I discuss 4 key reasons why interprofessional education is not likely to help pharmacy students learn to be effective collaborators, and suggest a better way forward.

First, after 3 decades of scientific inquiry, it is still unclear whether interprofessional education should be implemented at the undergraduate, postgraduate, or practice level., ${ }^{4,5}$ Many scholars believe that we should socialize students early into a more collaborative, "health care team" identity, but others argue that it is impossible for preclinical students to engage in interprofessional education activities - including role discussion and negotiationwhen they do not know their future clinical role. Interprofessional education might thus be developmentally inappropriate. Moreover, as noted elsewhere, it is unfair to task students with changing the health care system, as interprofessional education does. ${ }^{6}$ Undergraduate-level models train students to expect collaborative work environments, yet students and graduates often confront a reality that is disenchantingly otherwise, despite undeniable improvements in collaborative practice over the past decades.-9 As newcomers in an inertial system, they are rarely in positions to confront harmful and unsafe professional hierarchies. Consequently, the impact of undergraduate-level interprofessional education on the system is likely lower than approaches aimed at changing collaborative practice in situ.

Second, interprofessional education has been widely criticized for being atheoretical and ahistorical, ${ }^{6,10-13}$ yet its model of "learning with, from, and about" other healthcare professional 
students ${ }^{14}$ hinges implicitly on contact theory. First articulated in 1954 by Allport, in the context of American race relations, this theory suggests that bringing members of different groups together should reduce prejudice and improve intergroup relationships. ${ }^{15}$ Although a recent literature review presents evidence in support of contact theory, ${ }^{16}$ it also suggests that individuals who are "coerced" into intergroup interactions often experience negative contact, whereby stereotypes are confirmed and prejudice reinforced, and that positive intergroup contact requires equal status among participants, ${ }^{16}$ something that even proponents of contact theory agree is hard to achieve during interprofessional education activities. ${ }^{17}$

This is distressing news for the field. Indeed, a growing corpus of critical interprofessional education research from Canada, ${ }^{18}$ Australia, ${ }^{19}$ New Zealand, ${ }^{13}$ and the United States ${ }^{4,20}$ hints at both the reinforcement of professional stereotypes among students and widespread frustration with interprofessional education's tacit acceptance of the hierarchy of professions. Moreover, coercing students from different professions to come together might be defeating the intervention's very purpose. Enabling contact among health care professionals is not enough; had it been, their history of delivering care together would arguably have ironed out the kinks of collaborative care. We desperately need a more elaborate view of how the professions come together upon which to anchor education for collaboration, ${ }^{2,6}$ and could follow the lead of scholars who have used other social theories to provide more nuanced portraits of interprofessional relationships and interprofessional education. ${ }^{4,11,21}$

Third, the aim of interprofessional education is to improve patient care outcomes by educating collaboration-ready professionals who can transform health care delivery. It is absolutely reasonable to expect an educational intervention such as this to change the attitudes and beliefs of students (although, as noted above, coerced interaction might invite backlash). The larger claim that interprofessional education can actually change health care practices, however, rests on very fragile grounds. A recent systematic review covering 30 years of research found that the results of the mere 15 studies that met the inclusion criteria were so inconsistent that "it is not possible to draw generalisable inferences about the key elements of [interprofessional education] and its effectiveness." 22 Similarly, the World Health Organization's 2013 guidelines for the education of health care professionals found "no practice-level impact assessment" of interprofessional education on patient care, and recommended implementing interprofessional education "only in the context of rigorous research." ${ }^{14}$ Of course, lack of evidence about effectiveness is not evidence of ineffectiveness, and educators know that documenting the impact of educational interventions is extremely difficult. But what if we stopped searching for the key to education for collaboration under the interprofessional education lamppost and started looking elsewhere?
Finally, as noted by the World Health Organization, interprofessional education requires a "significant layer of coordination" to be developed and implemented. ${ }^{14}$ Anyone who has been involved in interprofessional education knows how difficult it is in many cases to find (qualified) volunteer facilitators and rooms to host the small groups upon which effective interprofessional education is predicated, ${ }^{5,13,14}$ how hard it is to motivate students, to track and assess their involvement, and to provide meaningful feedback, ${ }^{13}$ and how tedious it is to coordinate student schedules across several faculties while also developing and maintaining organizational buy-in. These challenges explain why interprofessional education often requires the work of several (paid) professionals, who must be wizards of event, space, and people management.

The literature fully acknowledges these pragmatic constraints and their negative impact on interprofessional education, in terms of both the quality of the offerings and the educational experience itself. ${ }^{4,5,14,23}$ It rarely, however, considers an alternative model: uniprofessional education for collaboration. Because collaboration is a core competency of the Association of Faculties of Pharmacy of Canada, its teaching is part of the educational mandate of all Canadian faculties of pharmacy. As such, uniprofessional education can likely be integrated much more easily and cheaply into the pharmacy curriculum than can interprofessional education.

In conclusion, we as a community have to recognize that education rarely solves social problems singlehandedly. Until we accept and embrace the complexity of professional interactions, as determined by systemic - that is, sociological, societal, historical, legal, and organizational—factors, we will not be able to transform them. Interprofessional education overpromises and underdelivers. As an expensive, theoretically naive, individual-level solution that might actually reinforce professional stereotypes, interprofessional education at the undergraduate level is likely counterproductive. Merely teaching health care providers that they should listen to each other, know their colleagues' roles, and be good teammates will not transform the structural issues that make patient-centred, collaborative care difficult. Education for collaboration in general and interprofessional education more specifically can go only so far in transforming the health care system, and should thus form only one aspect of our quest to improve patient outcomes.

This being said, what kind of education for collaboration should we embrace? Given the evidence and shortcomings discussed above, it seems that the most productive strategy might be to educate undergraduates uniprofessionally. Instructors could address system-level issues, discuss professional stereotypes, and teach strategies for negotiating power differentials and difficult situations. In doing so, they would lay the groundwork for more effective, reflexive collaborative practice. Furthermore, practicebased interprofessional education could be implemented during clinical rotations and in practice settings, where much change is still needed. 


\section{References}

1. Paradis E, Reeves $S$. Key trends in interprofessional research: a macrosociological analysis from 1970 to 2010. J Interprof Care. 2013;27(2):113-22.

2. Barrow M. Conflict in context: designing authentic teamwork education. Med Educ. 2012;46(10):926-7.

3. Frenk J, Chen L, Bhutta ZA, Cohen J, Crisp N, Evans T, et al. Health professionals for a new century: transforming education to strengthen health systems in an interdependent world. Lancet. 2010;376(9756):1923-58.

4. Michalec B, Hafferty FW. Role theory and the practice of interprofessional education: a critical appraisal and a call to sociologists. Soc Theory Health. 2015;13(2):180-201.

5. Reeves S, Tassone M, Parker K, Wagner SJ, Simmons B. Interprofessional education: an overview of key developments in the past three decades. Work. 2012;41(3):233-45.

6. Paradis E, Whitehead CR. Louder than words: power and conflict in interprofessional education articles, 1954-2013. Med Educ. 2015;49(4): 399-407.

7. Reeves S, Nelson S, Zwarenstein M. The doctor-nurse game in the age of interprofessional care: a view from Canada. Nurs Inq. 2008;15(1):1-2.

8. Stein LI. The doctor-nurse game. Arch Gen Psychiatry. 1967;16(6):699.

9. Stein LI, Watts DT, Howell T. The doctor-nurse game revisited. $N$ Engl J Med. 1990;322(8):546-9.

10. Clark PG. What would a theory of interprofessional education look like? Some suggestions for developing a theoretical framework for teamwork training. J Interprof Care. 2006;20(6):577-89.

11. Burford B. Group processes in medical education: learning from social identity theory. Med Educ. 2012;46(2):143-52.

12. Kuper A, Whitehead C. The paradox of interprofessional education: IPE as a mechanism of maintaining physician power? J Interprof Care. 2012; 26(5):347-9.

13. Barrow M, McKimm J, Gasquoine S. The policy and the practice: earlycareer doctors and nurses as leaders and followers in the delivery of health care. Adv Health Sci Educ. 2011;16(1):17-29.

14. Transforming and scaling up health professionals' education and training: World Health Organization guidelines. Geneva [Switzerland]: World Health Organization; 2013.

15. Allport GW. The nature of prejudice. Reading (MA): Addison-Wesley; 1954.
16. Pettigrew TF, Tropp LR, Wagner U, Christ O. Recent advances in intergroup contact theory. Int J Intercult Rel. 2011;35(3):271-80.

17. Hean S, Dickinson C. The contact hypothesis: an exploration of its further potential in interprofessional education. J Interprof Care. 2005;19(5): 480-91.

18. Baker L, Egan-Lee E, Martimianakis MA, Reeves S. Relationships of power: implications for interprofessional education. J Interprof Care. 2011;25(2): 98-104.

19. Hudson JN, Lethbridge A, Vella S, Caputi P. Decline in medical students' attitudes to interprofessional learning and patient-centredness. Med Educ. 2016;50(5):550-9.

20. Kashner TM, Hettler DL, Zeiss RA, Aron DC, Bernett DS, Brannen JL, et al. Has interprofessional education changed learning preferences? A national perspective. Health Serv Res. 2016 [Epub ahead of print].

21. Baker L, Egan-Lee E, Martimianakis M, Reeves S. Relationships of power: implications for interprofessional education and practice. I Interprof Care. 2011;25:98-104.

22. Reeves S, Perrier L, Goldman J, Freeth D, Zwarenstein M. Interprofessional education: effects on professional practice and healthcare outcomes (update). Cochrane Database Syst Rev. 2013;3(3):CD002213.

23. Lawlis TR, Anson J, Greenfield D. Barriers and enablers that influence sustainable interprofessional education: a literature review. J Interprof Care. 2014;28(4):305-10

Elise Paradis, MA, PhD

Assistant Professor

Canada Research Chair in Collaborative Healthcare Practice

Leslie Dan Faculty of Pharmacy

University of Toronto

Toronto, Ontario

Competing interests: None declared.

\section{ON THE FRONT COVER}

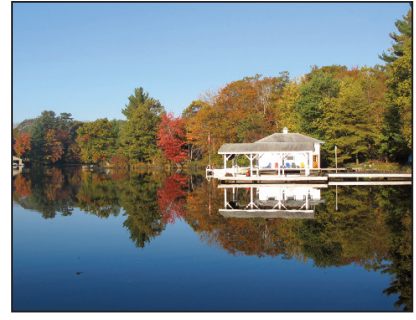

\section{Autumn in Port Carling, Ontario}

A highlight of autumn in Ontario is watching the leaves turn red, orange, and yellow. This picture was taken by Heather Kertland (Clinical Pharmacy Specialist/Leader at St Michael's Hospital in Toronto) on the dock at a cottage during Thanksgiving weekend, 2011. Heather took advantage of the calm water to capture reflections of the fall foliage.

The CJHP would be pleased to consider photographs featuring Canadian scenery taken by CSHP members for use on the front cover of the journal. If you would like to submit a photograph, please send an electronic copy (minimum resolution $300 \mathrm{dpi}$ ) to cjhpedit@cshp.ca. 